\title{
Inorganic/Organic Hybrid Nanocomposites involving OMMT Clay and Cyanate ester-Siloxane-modified Epoxy Resin: Thermal, Dielectric and Morphological Properties
}

\author{
S. Nagendiran ${ }^{1}$, C. Karikal Chozhan ${ }^{1}$, M. K. Alagar ${ }^{1} *$, I. Hamerton ${ }^{2}$ \\ ${ }^{I}$ Department of Chemical Engineering, Anna University, Chennai 600 025, India. \\ ${ }^{2}$ Chemistry Division, School of Biomedical and Molecular Sciences, University of Surrey, \\ Guildford, Surrey GU2 7XH, UK.
}

\begin{abstract}
Organic-inorganic hybrids involving cyanate ester and HTPDMS (hydroxyl terminated polydimethylsiloxane) modified epoxy, filled with organo-modified Montmorillonite (MMT) clay nanocomposites are prepared via in situ polymerization by the homogeneous dispersion of various percentages ( 1 to $5 \% \mathrm{w} / \mathrm{w}$ ). The resulting homogeneous epoxyclay hybrids are modified with 10\% HTPDMS and $\gamma$-aminopropyltriethoxysilane ( $\gamma$-APS) coupling agent in the presence of a tin catalyst. The siliconized epoxy-clay prepolymers are further modified separately with $10 \mathrm{wt}-\%$ of three different cyanate ester monomers (viz 2,2'-bis(4-cyanatophenyl)propane, 1,1'-bis(3-methyl-4-cyanatophenyl)cyclohexane and 1,3-dicyanatobenzene) and cured with diaminodiphenylmethane. The reactions involved during the curing process between epoxy, siloxane and cyanate are confirmed by FTIR and the results of differential scanning calorimetry and dynamic mechanical analysis show that the glass transition temperatures of the clay filled hybrid epoxy systems are lower than that of neat epoxy. The data obtained from thermal studies indicate that the incorporation of nano clay into cyanate ester and siloxane modified epoxy hybrid systems improves thermal stability and the morphologies of the siloxane containing epoxy-clay hybrid systems show heterogeneous character, due to the partial incompatibility of HTPDMS. Scanning electron microscopy reveals that phase separation, induced by the polymerization, occurs in the HTPDMS modified epoxy hybrids to yield spherical particles of siloxane-rich phase, which are uniformly dispersed in the continuous epoxy matrix. The exfoliation of organoclay is ascertained from the $\mathrm{X}$ -
\end{abstract}


ray diffraction pattern and shows interlayer spacings of between 3.42 and $8.50 \AA$. By increasing the percentage of clay and introducing both cyanate ester and siloxane into epoxy resin reduces the degree of water uptake. Hybrid epoxy nanocomposites containing higher organo modified MMT clay contents (up to $5 \mathrm{wt}-\%$ ) display more pronounced improvements in thermal properties and moisture resistance than corresponding unmodified epoxy matrices.

Keywords: MMT clay, cyanate ester and HTPDMS toughened epoxy, thermal and morphology properties.

\section{Introduction}

Nanostructured hybrid organic-inorganic composites have attracted considerable attention recently, both from the perspectives of fundamental research and their technological application $[1,2,3]$. One approach to preparing these materials is via solgel processing, wherein the inorganic components are formed in situ through hydrolysis and condensation of metal oxide precursors, while the organic matrix undergoes simultaneous polymerization. However, the sol-gel approach is limited by the evolution of volatile byproducts and concomitant shrinkage when the hybrid is processed at elevated temperatures [4,5]. Alternatively, the incorporation of layered silicates can be used as inorganic components for the construction of nanostructured hybrid polymer composites [6,7]. Polymer-clay nanocomposites, as these materials are known, possess dramatically improved properties due to nanometre-sized dispersions of organically modified clay in the polymer matrix [8]. For example, incorporation of a few weight percent of clay in polymeric matrices brings appreciable increases in thermal and mechanical properties compared with their unmodified counterparts [9] and researchers at Toyota have demonstrated that nylon-6, following exfoliation with an inorganic filler possesses greatly improved thermal, mechanical, barrier, and even flame-retardant properties [10,11]. The general approach has since been extended to many other commercial polymers, including polyimides, polyamides, unsaturated polyesters, poly(oxyethylene), polystyrene, polystyrene maleic anhydride, amine-terminated 
butadiene acrylonitrile (ATBN), poly(methyl methyacrylate), polypropylene, poly(oligo(oxyethylene)) methacrylates, polyurethane and poly(butylene terephthalate) [12].

There has been intense interest in crosslinked epoxy-clay nanocomposites because in addition to the aforementioned thermal and mechanical properties, such materials also have excellent chemical resistance, good electrical insulating properties, good adhesion to glass and metals, and can be easily fabricated $[13,14,15]$. The variety of properties of epoxy resins make suitable to meet the performance requirements of applications, include areas such as construction, electronics, adhesives, coatings and space vehicles $[12,16]$. Messersmith and Giannelis [17] reported that exfoliated epoxy/clay nanocomposite could be obtained when anhydride was used as a curing agent. Wang and Pinnavaia [18] and Lan et al. [19,20] conducted more intensive investigation on epoxy/clay nanocomposites and found that the exfoliation behavior of clay was determined mainly by the structure of the organoclay and the curing temperature adopted. However, because of inherently brittle nature, additives and modifiers are generally used to improve their physical, thermal and mechanical properties. Ashok Kumar and Alagar et al. [21] studied the hydroxyl terminated polydimethylsiloxane (HTPDMS) as the toughening agent for the epoxy resin and they found that HTPDMS is the most suitable polymer because of it's versatile behavior like flexibility due to $-\mathrm{Si}-\mathrm{O}-\mathrm{Si}$ - linkage, high thermal and thermooxidative stability, high moisture resistance, good dielectric properties, excellent UV and chemical resistance. Dinakar and Alagar [22] investigated the modification of epoxy resin with a co-reactive component cyanate esters and the formation of flexible oxazolidinone aliphatic cyclic ring. Cyanate esters chemically react with epoxy and forms hybrid polymer, which exhibits low dielectric (2.5-3.1), thermal and mechanical characteristics and low water absorption (0.6-2.5 wt-\%), excellent heat and chemical resistance, low volume shrinkage and rendering the material of choice in high performance applications $[23,24,25]$. Though the incorporation of siloxane and cyanate ester into an epoxy system improves its impact strength and thermal stability [21,22,23,24,25,26], it also reduces the stress-strain properties and glass transition temperature. Thus, in order to prevent the loss of stress-strain properties, organically modified montmorollonite (MMT) clay (0-5 wt-\%) has been incorporated with siliconized cyanate ester-epoxy matrices via a cation 
exchange process to form an exfoliated structure with improved thermo-mechanical properties [16,27].

Hence, the present study attempts to improve both the toughness and thermal behavior of an epoxy resin without an appreciable loss in strength properties by forming exfoliated networks of siliconized cyanate ester-epoxy/organically modified MMT clay using HTPDMS and three different cyanate esters as chemical modifiers via an in situ polymerization method. The thermal and morphological properties of the hybrid epoxy nanocomposites are studied and compared with varying concentration of clay and cyanate esters.

\section{Experimental}

\subsection{Materials}

The commercially available epoxy resin (diglycidyl ether of bisphenol A, DGEBA) LY 556, having an epoxy equivalent weight of about 180-190 $\mathrm{g} \mathrm{mol}^{-1}$, and diaminodiphenylmethane (DDM) were obtained from Ciba-Geigy Ltd., India. Cyanogen bromide, cyclohexanone, bisphenol A, resorcinol and $o$-cresol (SRL, India) were used as received without further purification. Montmorillonite K10 and HTPDMS, having RMM 17,000-18,000 $\mathrm{g} \mathrm{mol}^{-1}$ and viscosity 800-900 cP, were purchased from Aldrich Chemical Corp., USA. The cross linking agent $\gamma$-APS and dibutyltindilaurate catalyst were obtained from Lancaster (USA) and Merck (Germany) respectively.

\subsection{Synthesis of 1,1-bis(3-methyl-4-hydroxy phenyl) cyclohexane}

Cyclohexanone (0.05 mol.), o-cresol (0.1 mol.) and a mixture of hydrochloric acid and acetic acid $(2: 1 \mathrm{v} / \mathrm{v})$ were reacted at $50{ }^{\circ} \mathrm{C}$. The resulting pink coloured product was isolated, washed with water to remove acid and dissolved in $2 \mathrm{M} \mathrm{NaOH}$ solution. The following day, the solution was filtered to remove resinous material, acidified with dilute hydrochloric acid, filtered, washed with distilled water and dried at $90-100{ }^{\circ} \mathrm{C}$ to yield the purified product $\left(81 \%\right.$, m.p. $\left.=186^{\circ} \mathrm{C}\right)$.

IR (KBr, $\left.\mathrm{cm}^{-1}\right)$ : 3536, $3407(\mathrm{O}-\mathrm{H}), 2926,1600,1506,1450,1268,1174,1119$, 1032, 895. ${ }^{1} \mathrm{H}-\mathrm{NMR}(\mathrm{ppm}): \delta$ 1.24-2.03 (m, 4H), 2.31 (s, 6H), 3.24-3.45 (m, 6H), 6.67 $(\mathrm{d}, J=8.3 \mathrm{~Hz}, 2 \mathrm{H}), 6.86(\mathrm{~d}, J=8.3 \mathrm{~Hz}, 2 \mathrm{H}), 8.54(\mathrm{~s}, 2 \mathrm{H}) .{ }^{13} \mathrm{C}-\mathrm{NMR}\left(\mathrm{ppm}, \mathrm{d}_{6}-\mathrm{CDCl}_{3}\right): \delta$ 
154, 139.6, 129.4, 125.0, 123.6, 114.3 (C aromatic); 44.3, 37.0, 26.3, 22.8, 16.5 (C aliphatic).

\subsection{Synthesis of cyanate ester monomers}

To a 1 litre three-necked flask fitted with paddle stirrer, and nitrogen inlet, were added: diol $\left(1 \mathrm{~mol}\right.$.) in acetone $\left(600 \mathrm{~cm}^{3}\right)$. Cyanogen bromide $(2 \mathrm{~mol}$.) in acetone (100 $\left.\mathrm{cm}^{3}\right)$ was added drop wise and followed by triethylamine (2.2 mol.) - also added drop wise. The reaction was maintained at $-15{ }^{\circ} \mathrm{C}$ for $1 \mathrm{hr}$, during which time the contents of the vessel changed to pale yellow in colour, and filtered under vacuum, to separate triethylammonium bromide. The product, was precipitated from acetone by adding ice cold water to yield a white solid, which was filtered and recrystallized from water:methanol (1:1) under ice cold conditions (yields: 2,2'-bis(4cyanatophenyl)propane: $64 \%$, m.p. $=78{ }^{\circ} \mathrm{C} ; 1,1$ 'bis(3-methyl-4-cyanatophenyl) cyclohexane: $76 \%$, m.p. $=82.9^{\circ} \mathrm{C} ; 1,3$-dicyanatobenzene: $68 \%$, m.p. $=101{ }^{\circ} \mathrm{C}$ ).

\subsection{Preparation of siliconized epoxy prepolymer}

A fixed amount of epoxy resin, containing hydroxyl-terminated polydimethylsiloxane (10 wt-\%), a stoichiometric amount (with respect to the hydroxyl groups of HTPDMS) of $\gamma$-APS and a dibutyltindilaurate catalyst were thoroughly mixed at $90{ }^{\circ} \mathrm{C}$ for $30 \mathrm{~min}$. with constant stirring. The product was then degassed to remove ethanol formed during the condensation reaction between $\gamma$-APS and HTPDMS (scheme 2).

\subsection{Preparation of cyanate ester modified siliconized epoxy blends}

A fixed amount of siliconized epoxy resin, containing cyanate ester (10 wt-\%) and a stoichiometric amount (with respect to the epoxy) of diaminodiphenylmethane were blended thoroughly at $100{ }^{\circ} \mathrm{C}$ for $10 \mathrm{~min}$. with constant stirring. The product was then degassed, poured into a preheated mould and maintained at $140{ }^{\circ} \mathrm{C}(3 \mathrm{hr}$.) and postcured at $200{ }^{\circ} \mathrm{C}(2 \mathrm{hr})$. 


\subsection{Preparation of organically modified clay}

The crude montmorillonite clay (25 g) was pre-treated for $24 \mathrm{hrs}$. in a $0.1 \mathrm{~N}$ solution of $\mathrm{NaCl}\left(5 \mathrm{dm}^{3}\right)$ with continuous stirring at $70{ }^{\circ} \mathrm{C}$. Upon centrifugation of the solution at high speed, an opaque whitish layer accumulated at the bottom of the centrifuge tubes beneath a translucent gel. The gel was isolated and washed several times with deionised water until no chloride was detected. Then purified Na-montmorillonite clay was dried at $70{ }^{\circ} \mathrm{C}$ and stored in a dessicator prior to next step.

The purified montmorillonite clay (15 g) was dispersed in distilled water (1.2 $\left.\mathrm{dm}^{3}\right)$ at $80^{\circ} \mathrm{C}$. Cetylammonium bromide $(5.7 \mathrm{~g})$ in distilled water $\left(300 \mathrm{~cm}^{3}\right)$ was poured into the hot montmorillonite/water solution and stirred vigorously at $80{ }^{\circ} \mathrm{C}(1 \mathrm{hr}$.) after which time a white precipitate formed. The latter was isolated by filtration and washed several times with a hot water/ethanol (1:1) mixture until no bromide was detected in the filtrate by one drop of $0.1 \mathrm{~N} \mathrm{AgNO}_{3}$ solution. The cetylammonium ion exchanged montmorillonite was then dried for several days at $75{ }^{\circ} \mathrm{C}$, ground with a mortar and pestle, before the $<50 \mu \mathrm{m}$ fraction was collected. The organophilic clay was stored in a dessicator.

\subsection{Preparation of epoxy-clay nanocomposites}

Prior to curing, the epoxy resin was blended with the desired amount of organophilic clay at $70{ }^{\circ} \mathrm{C}(24 \mathrm{hr}$.). A stoichiometric amount of the curing agent corresponding to the epoxy equivalence was added. The product was subjected to vacuum to remove trapped air and then cast and cured at $140{ }^{\circ} \mathrm{C}(3 \mathrm{hr}$.). The castings were then post-cured at $200{ }^{\circ} \mathrm{C}(2 \mathrm{hr}$.) and finally removed from the mould and characterized.

\subsection{Characterization}

FTIR spectra were recorded using a Perkin-Elmer 781 infrared spectrometer: solid samples were presented as $\mathrm{KBr}$ pellets; viscous samples were analyzed as thin films on $\mathrm{KBr}$ pellets. ${ }^{1} \mathrm{H}$ - and ${ }^{13} \mathrm{C}$ - NMR spectra were recorded (in $\mathrm{CDCl}_{3}$ ) at $298 \mathrm{~K}$ on a Bruker $400 \mathrm{MHz}$ NMR spectrometer. 
Glass transition temperatures $\left(\mathrm{T}_{\mathrm{g}}\right)$ of the samples were determined using a Netzsch DSC 200PC (TA instruments USA) in the temperature range 30 to $300{ }^{\circ} \mathrm{C}$ at a heating rate of $10 \mathrm{~K} \mathrm{~min}^{-1}$ in a flowing nitrogen atmosphere. Thermogravimetric (TG) analysis was carried out using Thermal Analyst Netzsch STA 409PC (TA instruments USA) at a heating rate of $10 \mathrm{~K} \mathrm{~min}^{-1}$ in a flowing nitrogen atmosphere. The heat deflection temperature of the samples was tested as per ASTM D 648-72.

Dynamic mechanical analysis of the samples was determined using a Netzsch DMA 242 in the temperature range 50 to $250{ }^{\circ} \mathrm{C}$ in air $\left(1 \mathrm{~cm}^{3} \mathrm{~min}^{-1}\right)$ at a heating rate of 5 $\mathrm{K} \mathrm{min}^{-1}$ and a frequency of $20 \mathrm{~Hz}$. The water absorption of the samples was tested as per ASTM D 570.

The surface morphology of fractured surfaces of the samples were analysed using a scanning electron microscope (Leica Cambridge, Stereoscan Model 440) under vacuum conditions. X-ray diffraction analysis of powdered cured nanocomposites was performed using $\mathrm{Cu} \mathrm{K} \alpha$ radiation $(\lambda=1.54 \AA$ ) and the $d$-spacing was calculated by using the equation $2 d_{001} \sin \theta=\lambda$. Scans were taken over the $2 \theta$ range of $10-90^{\circ}$.

\section{Structure of the layered silicate clays}

The silicates formerly belonged to the general family of so-called 2:1 layered silicates: their crystal structures comprise layers made up of two silica tetrahedra fused to an edge-shared octahedral sheet of either alumina or magnesia (Fig. 1a). Stacking of the layers leads to a regular van der Waals' gap between the layers called the interlayer or gallery. The isomorphic substitution within the layers generates negative charges that are normally counterbalanced by cations residing in the interlayer and pristine layered silicates usually contain hydrated $\mathrm{Na}^{+}$or $\mathrm{K}^{+}$ions.

The ion-exchange reactions with cationic surfactants e.g., cetylammonium ions, render the normally hydrophilic silicate surface organophilic, which makes exfoliation or intercalation of many engineering polymers possible (Fig. 1b). The rôle of the alkylammonium cations in the organosilicates is to lower the surface energy of the inorganic component and improve the wetting characteristics with the polymer. Additionally, the alkylammonium cations can provide functional groups that can react with a polymer or initiate polymerization of its monomers to improve the strength of the 
interface between the inorganic component and the polymer. In this paper, amine functionalized cetylammonium cation is modified with Na-MMT clay (Fig. 2) and made to change its nature from organophobic to organophilic. Hence, the organoclay reacts strongly with DGEBA, increases the $d$-spacing between the clay layers and polymer and forms a delaminated structure with the epoxy polymer, which is confirmed by XRD analysis.

\section{Result and Discussion}

\subsection{Spectral analysis}

The reaction between the epoxy and $\gamma$-APS during the cure process of siliconized epoxy systems was confirmed by FT-IR spectral studies. The formation of the siliconized epoxy network structure proceeds in two steps (Scheme 2): the first involves the reaction between epoxide ring of the epoxy resin and amino group of the $\gamma$ aminopropyltriethoxysilane, which is confirmed by the disappearance of the epoxy band at $913 \mathrm{~cm}^{-1}$ and the appearance of a hydroxyl band at $3420 \mathrm{~cm}^{-1}$ (Fig. 3b). In the second step, the alkoxy groups present in the $\gamma$-aminopropyltriethoxysilane react with hydroxyl groups of hydroxyl-terminated polydimethylsiloxane. The appearance of two shoulder peaks in the $\gamma$-APS spectrum indicated the presence of -Si-C- and -Si-O-C- at 1084 and $1172 \mathrm{~cm}^{-1}$ respectively, whilst they merged in the case of HTPDMS modified epoxy at $1117 \mathrm{~cm}^{-1}$ due to the presence of $-\mathrm{Si}$-O-Si- linkage. However, the $-\mathrm{Si}-\mathrm{C}$ - band at 1084 $\mathrm{cm}^{-1}$ in the siliconized epoxy system overlaps with the -Si-O-Si- band and thus could not be observed clearly (Fig. 3c).

The reaction between the cyanate ester and siliconized epoxy proceeds in several steps (Scheme 3). The cyclotrimerisation of cyanate groups followed by the reaction with epoxy groups results in the formation of several intermediates including isocyanurate, oxazoline and oxazolidinone species [28,29,30,31,32,33]. In the case of the cyanate ester (CE-2), synthesized from the diol, the monomer showed a characteristic absorption band at $2253 \mathrm{~cm}^{-1}$, which vanished in the epoxy cured cyanate ester systems. The appearance of a new absorption band at $1750 \mathrm{~cm}^{-1}$ (Fig. 3e) is due to the formation of oxazolidinone, while other absorptions $\left(1650,1690\right.$ and $\left.1750 \mathrm{~cm}^{-1}\right)$ are due to the formation of the products such as oxazoline, isocyanurate and cyanurate respectively. It 
was also found that the reaction of epoxy and isocyanurate caused a considerable reduction in the intensity of the epoxy band at $914 \mathrm{~cm}^{-1}$.

The FT-IR spectrum of the DDM cured cyanate ester-siliconized epoxy system (Fig. 3f) showing the absorption at 1750 and $1690 \mathrm{~cm}^{-1}$, confirms the formation of oxazolidinone and isocyanurate. There is no $s$-triazine vibration visible at $1565 \mathrm{~cm}^{-1}$ which further confirms the conversion of cyanurate into oxazolidinone and isocyanurate by the reaction with epoxy resin.

\subsection{Thermal properties}

\subsubsection{Differential Scanning Calorimetry (DSC)}

Each of the DSC thermograms for all the samples displayed single glass transition temperatures and in each case this is attributed to the formation of epoxy nanocomposites in the form of an interpenetrating network (IPN). The values of glass transition temperature of the neat epoxy, filled and unfilled organoclay hybridized with cyanate ester-siloxane modified epoxy nanocomposites are presented in Fig. 4 and Table 1.

The DGEBA displayed a $\mathrm{T}_{\mathrm{g}}$ at $165^{\circ} \mathrm{C}$ and the incorporation of HTPDMS had no significant impact on this value (e.g. the $\mathrm{T}_{\mathrm{g}}$ for the 10\% HTPDMS modified epoxy system is $164{ }^{\circ} \mathrm{C}$ and this may be due to the presence of flexible and freely-rotating -SiO-Si- linkages). The single $\mathrm{T}_{\mathrm{g}}$ value obtained for the siliconized epoxy system indicates that the siloxane is chemically incorporated into the epoxy systems. The incorporation of cyanate esters into siliconized epoxy systems reduces the values of $T_{g}$ still further (Fig. 4a), due to the formation of aliphatic oxazolidinone, which decreases the effective crosslink density. Amongst the cyanate ester modified siliconized epoxy systems, the minimum decrease in the value of $T_{g}$ is obtained in the case of the CE-1 system due to the lower number of molecules and high aromaticity when compared with the same weight percentage of CE-2 and CE-3 modified siliconized epoxy systems. For example, the value of $\mathrm{T}_{\mathrm{g}}$ obtained for $10 \% \mathrm{CE}-1$ modified with $10 \%$ siliconized epoxy is $164{ }^{\circ} \mathrm{C}$ whereas the values for the same weight percentage of CE-2 and CE-3 modified siliconized epoxy system are $163{ }^{\circ} \mathrm{C}$ and $162{ }^{\circ} \mathrm{C}$ respectively. For the clay reinforced hybrid systems, it is observed that there is no significant reduction in the value of $\mathrm{T}_{\mathrm{g}}$ when the organoclay is reinforced with modified epoxy systems (Fig. 4b). A similar 
observation was also reported by number of investigators $[22,34,35]$ : the value of $\mathrm{T}_{\mathrm{g}}$ of the hybrid clay reinforced epoxy nanocomposites decreased with increasing concentration of clay up to $5 \mathrm{wt}-\%$. This may be attributed to the interference of the clay with crosslink density, catalyzed homopolymerization of epoxy during swelling period and the plasticization effect imparted by the presence of cetylammonium ion within the organoclay, perhaps the presence of a heterogeneous morphology by the introduction of siloxane into organoclay filled epoxy systems.

\subsubsection{Thermogravimetric (TG) Analysis}

The thermal stability of the filled and unfilled of organoclay with toughened epoxy hybrid systems was investigated with TG analysis. Consequently, improvements in thermal stability of epoxy networks, by incorporating organo modified MMT clay, cyanate ester and siloxane moieties, were observed for all the systems (both in terms of reduced rates of weight loss from segmental decomposition and increased ceramic yields). The effects of the incorporation of siloxane and cyanate ester on the weight loss for the epoxy and the clay reinforcement on the toughened epoxy systems are shown in Figs. 5a and $5 \mathrm{~b}$ respectively. The incorporation of siloxane and cyanate ester into the epoxy resin results in enhanced degradation temperature: there is a significant improvement in thermal degradation temperature for both siliconized epoxy and cyanate ester-siliconized epoxy systems (Fig. 5a). Thus, the temperatures required for 10, 30 and $50 \%$ weight losses of the unmodified epoxy - DDM systems are $363{ }^{\circ} \mathrm{C}, 384{ }^{\circ} \mathrm{C}$ and $391^{\circ} \mathrm{C}$ respectively, whereas the temperatures required to attain the same weight losses for the $10 \%$ siliconized epoxy system are found to be increased to $369{ }^{\circ} \mathrm{C}, 392{ }^{\circ} \mathrm{C}$ and $403{ }^{\circ} \mathrm{C}$ respectively.

The delay in degradation of the siliconized epoxy systems, when compared with unmodified epoxy system, is believed to be due to the presence of siloxane moiety, and its partial ionic nature and high bond energy of -Si-O-Si- linkage. Further improvements in the thermal stability of cyanate ester-siliconized epoxy systems were also observed when compared with siliconized epoxy systems. In this case, the pronounced improvement in thermal stability may be explained due to the presence of thermally stable isocyanurate and oxazolidinone structures formed by the cyclotrimerisation of 
cyanate esters and subsequent reaction with siliconized epoxide [23]. For example, the temperature required for 50\% weight loss of siliconized epoxy and (CE-2) cyanate estersiliconized epoxy are $403{ }^{\circ} \mathrm{C}$ and $418{ }^{\circ} \mathrm{C}$, respectively: this enhancement is believed to be due, in the main, to the synergistic effect of the cyanate and the HTPDMS present in the epoxy systems. Among the cyanate esters (CE-1, CE-2 and CE-3) modified siliconized epoxy systems, it is observed that the CE-2 modified system yields a higher thermal degradation temperature than for CE-1 and CE-3 modified systems, due to the presence of a more complex ring structure. Thus, the temperature required for a weight loss of $50 \%$ in the CE- 2 modified system is $526{ }^{\circ} \mathrm{C}$, whereas the degradation temperature for the same percentage weight loss of CE-1 and CE-3 are $501{ }^{\circ} \mathrm{C}$ and $514{ }^{\circ} \mathrm{C}$, respectively.

On addition of 1,3 and 5 wt $\%$ organoclay into the cyanate ester-siliconized epoxy, the temperature required for $50 \%$ weight loss is further increased to $446{ }^{\circ} \mathrm{C}, 486$ ${ }^{\circ} \mathrm{C}$ and $526{ }^{\circ} \mathrm{C}$ respectively with a higher char yield of $30-40 \%$ at $799{ }^{\circ} \mathrm{C}$. It is clearly observed that the clay reinforced cyanate ester-siliconized epoxy systems exhibited increased rates of degradation and higher char yields with increasing clay concentration up to $5 \mathrm{wt} \%$ when compared with unfilled clay system (Fig. 5b). This supports the hypothesis involving the formation a barrier by the introduction of clay to undergo degradation and stabilize the char layer. There is also an appreciable improvement in the percentage of char yield formed following the introduction of both cyanate ester and HTPDMS into the epoxy system (Fig. 6) and this is believed to result from the formation of a thermally stable heterocyclic oxazolidinone ring structure by the reaction with epoxy and high bond energy of siloxane linkage. It is also observed that the increasing percentage of clay increases the formation of char yield due to the presence of aluminaand silica-like inorganic contents in the clay. Maximum char yields were observed in cyanate ester-siliconized epoxy nanocomposite systems conrtaining 5 wt $\%$ of organoclay reinforcement.

\subsubsection{Heat Distortion Temperature (HDT)}

HDT measurements were carried out to determine the thermomechanical behaviour of hybrid clay-epoxy systems and the data are presented in Fig. 7 and Table 1. From the latter, it is evident that the HDT is significantly affected by the introduction of 
siloxane and cyanate ester into epoxy system. This observation may be explained due to the presence of flexible -Si-O-Si- linkage in HTPDMS and the formation of oxazolidinone by the reaction of isocyanurate with epoxy, which in turn reduces the crosslink density. Fig. 7 shows that the values of HDT further decrease with increasing percentage of clay from 1 to $5 \mathrm{wt} \%$ due to the interference of the organoclay with crosslink density or may be the presence of heterogeneity by the introduction of siloxane into hybrid clay-epoxy systems. Among the cyanate esters, the values obtained for HDT for CE-1 is $141{ }^{\circ} \mathrm{C}$, whereas the values of HDT for CE-2 and CE-3 are $140{ }^{\circ} \mathrm{C}$ and $137^{\circ} \mathrm{C}$, respectively. Owing to the presence of higher aromaticity and lower number of molecules in CE-1 involved systems, the value obtained for HDT of CE-1 is slightly higher than other cyanate esters involved systems.

\subsection{Dynamic Mechanical Analysis (DMA)}

The dynamic mechanical spectra of both the unfilled and filled clay-cyanate esters and siloxane modified epoxy nanocomposites are shown in Fig. 8 as plots of $\tan \delta$ as functions of temperature; the major transitions (viz. $\alpha$-transitions) at $c a .165{ }^{\circ} \mathrm{C}$ are assigned to the glass-rubber transitions of the materials. The $\alpha$-transition becomes slightly shifted to the lower temperature upon adding the cyanate ester and HTPDMS into the DGEBA epoxy systems, while Fig. 8a clearly displays a single $\alpha$-transition for siliconized epoxy system and cyanate ester-siliconized epoxy at $c a .164{ }^{\circ} \mathrm{C}$ in both cases, which could be related to the glass-rubber transition. The siloxane and cyanate ester introduced epoxy systems reduce the crosslink density and subsequently glass-rubber transition shifted to lower temperature [21,22,25]. The lower crosslink density is confirmed by the greatest height of the delta relaxation observed in Fig. 8a, which is indicative of greater relaxation strength when compared with neat epoxy. The formation of aliphatic oxazolidinone rings by the reaction with epoxy and the presence of freelyrotating -Si-O-Si- linkages in HTPDMS by the introduction of cyanate ester and HTPDMS respectively, both affect the epoxy-DDM crosslink density and hence reduce $\mathrm{T}_{\mathrm{g}}$.

For the hybrid clay-epoxy systems containing organo modified MMT clay, it is seen that the primary transition (Fig. 8b) is further shifted to a lower temperature upon 
introducing the organoclay into cyanate ester-siliconized epoxy system. This may be a consequence of the inclusion of clay imparting greater free volume in the hybrid systems which, in turn, facilities the motion of the hydroxyether structural unit $\left(-\mathrm{O}-\mathrm{CH}_{2}-\mathrm{CH}(\mathrm{OH})\right.$ $\mathrm{CH}_{2^{-}}$) and diphenyl groups of the amine cured epoxy. Alternatively, it may reflect catalyzed homopolymerization of the epoxy by cetylammonium cations during the swelling period or the formation of heterogeneous morphology by the introduction of HTPDMS. This result, i.e. that the organic-inorganic clay hybrids display lower glass transition temperatures, is in good agreement with those obtained by means of DSC. The effect on the $T_{g}$ by the addition of organoclay into epoxy has been widely studied, with many investigators reporting an increase in $\mathrm{T}_{\mathrm{g}}$ values, whereas others found a slight decrease [27] or no change. Dinakaran et al. [22] and Hussain et al. [34] reported a decrease in $\mathrm{T}_{\mathrm{g}}$ for hybrid clay-epoxy systems similar to the results obtained and reported in the present work. The lower relaxation strength in organoclay filled toughened epoxy systems than unfilled clay system, which is observed in Fig. 8b., may be due to the exfoliation of the polymer molecules between the clay layers greatly reducing their molecular mobility. The latter is confirmed by XRD analysis, since the relaxation strength is associated with molecular mobility [22].

\subsection{Water absorption analysis}

The percentage water absorption of unmodified epoxy and organo clay, cyanate ester and HTPDMS modified epoxy are presented in Table 1. The introduction of inherently hydrophobic - $\mathrm{Si}-\mathrm{O}-\mathrm{Si}$ - siloxane linkages containing HTPDMS into the DGEBA epoxy system decreases the observed water absorption and a further reduction in this parameter results from the incorporation of cyanate ester into siliconized epoxy system. The percentage of water uptake of siliconized epoxy system is 0.11 , whereas the CE-1, CE-2 and CE-3 modified siliconized epoxy systems shows $0.10,0.11$ and 0.10 respectively. This may be attributed to the negligible tendency of moisture absorption nature of cyanate ester networks. Becker et al. [35] found that the neat epoxy systems generally absorb more water than the layered silicate composite materials by the equilibrium values. They correlated the values of the diffusion behavior of water into epoxy systems by using Fick's second law of diffusion (one-dimension), 


$$
\frac{\partial \mathrm{C}}{\partial \mathrm{t}}=\mathrm{D} \frac{\partial^{2} \mathrm{C}}{\partial \mathrm{x}^{2}}
$$

and Crank's simplified equation

$$
\frac{\mathrm{M}_{\mathrm{t}}}{\mathrm{M}_{\infty}}=\frac{4}{\mathrm{~L} \sqrt{ }_{\infty}} \sqrt{\mathrm{Dt}}
$$

Thus, they found that the no clear trend existed with varying organoclay concentration, while Massam and Pinnavaia [31] find that the rate of water uptake varied with clay concentration, and not the equilibrium uptake. Fig. 9 shows that the dramatically decreasing trend in organically modified clay filled cyanate-siliconized epoxy systems $[22,28,29]$ and this may be due to the fact that the decrease in permeability influenced by the exfoliated structure combined with the inherently hydrophobic natures of the cyanate ester and HTPDMS in the epoxy-clay hybrid systems.

\subsection{Scanning Electron Microscopic Investigation (SEM)}

The morphology of the organic-inorganic hybrid systems was investigated by means of SEM and shown in Fig. 10. SEM photograph in Fig. 10b clearly prove that the organoclay filled epoxy are homogenous with no apparent phase separation between silicate layers and epoxy matrix with excellent adhesion between the MMT layers and the epoxy matrix [22,12]. The excellent adhesion could be due to the formation of intermolecular specific interactions between cetylammonium ion modified clay and DGEBA, and hence formed exfoliated structure. The homogeneous dispersion of epoxyclay hybrid systems gradually became highly translucent with polymerization process by the introduction of HTPDMS in the system and shows heterogeneous morphology. The occurrence of possible phase separation is induced by the polymerization of siloxane and the partial incompatibility of HTPDMS with epoxy. It is seen that the discrete spherical siloxane-rich particles were uniformly dispersed in the continuous epoxy matrix as shown in Fig. 10c, which further confirmed the visual observation of translucence. This may be due to the fact that HTPDMS is chemically bonded with epoxy resin through $\gamma$-APS and the two phase morphology with uniformly dispersed domain is characteristic of phase separation. 
Dinakaran et al. [22] reported a homogeneous morphology for both cyanate ester modified epoxy systems and organoclay modified epoxy systems. The fractured surface of the organoclay filled cyanate ester-siliconized epoxy systems reveals the uniform dispersion of the siloxane moiety through the crosslinking agent in the heterogeneous morphology by the partial incompatibility of HTPDMS with epoxy-clay exfoliated systems as shown in Fig. 10d.

\subsection{X-Ray Diffraction analysis (XRD)}

The XRD profiles of hybrid epoxy-clay nanocomposites are shown in Fig. 11 and the epoxy systems modified with organo clay show the diffraction peaks which are identical to those previously reported for similar systems [22,27]. In Fig. 11, XRD patterns reveal the changes in the basal spacing during the preparation process of the epoxy-clay composites, with characteristic diffraction peaks present at $2 \theta=26^{\circ}\left(\mathrm{d}_{001}=\right.$ $3.42 \AA)$ for the organo clay. The diffraction peaks at $2 \theta=15.5^{\circ}\left(\mathrm{d}_{001}=5.70 \AA\right)$ represent the organo clay modified epoxy after a swelling period of $8 \mathrm{hrs}$ at $70{ }^{\circ} \mathrm{C}$, when compared to the original clay this displays a slightly reduced value of $2 \theta$ (large $\mathrm{d}$ spacing) to produce a pattern consistent with intercalation. The increased d-spacing suggests the organic molecule of cetylammonium ion diffused into the gallery between organoMMT clay and epoxy. Remarkably, on continued heating at the same temperature, the peaks broadened at $2 \theta=10.4^{\circ}\left(\mathrm{d}_{001}=8.50 \AA\right)$ and nearly disappeared after the period of $24 \mathrm{hrs}$ swelling, suggesting the formation of exfoliated structure. The exfoliation of the clay layers is caused by diffusion of epoxy molecules into clay galleries, the d-spacing between all pairs of clay layers should increase and assume a Gaussian distribution. The increase in corresponding d-spacing from 3.42 to $8.50 \AA$ suggests a high degree of adsorption of epoxy and cetylammonium ion that is held by van der Waals' forces. Since the interlayer surface is organophilic and has a great tendency to adsorb organic molecules, an exfoliated nanocomposite is achieved. However, it was observed that dspacing increased from an intercalated state to an exfoliated state only after swelling was continued for a specified period of time, indicating that the transition might have taken place suddenly or over a very short period of time. This is in good agreement with observations made by both Park et al. [28] and Becker et al. [32]. 
The introduction of HTPDMS into hybrid clay-epoxy systems leads to the presence of diffraction peaks at $2 \theta=11.5^{\circ}\left(\mathrm{d}_{001}=7.68 \AA\right)$, which indicates negligible reduction of d-spacing and hence that an exfoliated structure in the hybrid systems has been only slightly effected, due to the heterogeneous morphology. Hussain et al. [27] reported that the presence of a phosphorous moiety in the epoxy decreases the exfoliation of clay particles, and attributed this and the increase in reaction rate to the possibility of the epoxy undergoing enhanced curing at the side of the galleries (due to the presence of phosphorus). In order to avoid this problem, in the present study an attempt has been made to retain the exfoliated structure in the siloxane modified hybrid systems. The absence of diffraction peak is observed from Fig. 11a and 11b corresponding to ordered clay structures in the cured samples, even when the clay loading was increased to $5 \mathrm{wt} \%$ in the HTPDMS and cyanate ester modified hybrid systems. This is confirmed that the organoMMT clay has been completely exfoliated in the hybrid systems.

\section{Conclusions}

The hybrid clay-epoxy nanocomposites were prepared by initiating in situ polymerization of DGEBA and DDM with organically modified MMT clay as the delaminated structure at clay loadings of up $5 \mathrm{wt} \%$. The delaminated hybrid clay-epoxy system was toughened by the addition of $10 \mathrm{wt} \%$ of HTPDMS and $10 \mathrm{wt} \%$ of several cyanate esters and the co-reactions between HTPDMS, the cyanate esters and the epoxy were ascertained from FT-IR analysis. The glass transition behavior of the hybrid epoxy nanocomposites was investigated by means of DSC and DMA and compared with neat epoxy, the clay filled cyanate ester-siloxane toughened epoxy hybrid systems displayed minor reductions in glass transition temperatures and it proposed that increases in free volume result from (a) the cetylammonium ion treated MMT clay and (b) the combined effect of the formation of alicyclic oxazolidinone ring (reaction of cyanate ester with epoxy) and free rotation of the-Si-O-Si- linkage presence in HTPDMS.

When clay loadings of up to $5 \%$ are introduced and dispersed into the hybrid epoxy systems, the nanocomposites displayed pronounced improvements in thermal stability and char yield, lower $\alpha$-transition and greater relaxation strengths and reduced water uptake when compared to the neat epoxy system. As the morphologies of DGEBA, 
DDM and organically modified MMT clay were homogeneous, this suggests that there is interfacial interaction between cetylammonium ion treated MMT clay and DGEBA, while the presence of the partly incompatible HTPDMS (particularly the siloxane moiety) in the clay modified epoxy hybrids, induces phase separation to yield spherical siloxane particles dispersed uniformly in the continuous epoxy matrix. Diffusion of the epoxy polymer into the clay layers leads to exfoliation and the resulting structure is retained in the multi-component hybrid systems.

\section{Acknowledgements}

The authors thank the Defence Research and Development Organization (DRDO), Government of India, New Delhi -110 011, for financial support. We wish to thank Dr. P.G. Gnanasundram, Professor of Chemistry, A.C. College of Technology, Anna University, Chennai 600025 for his assistance. We acknowledge the following institutions: IIT Madras, University of Madras and CLRI for characterization analysis.

\section{Summary of Tables and Figures}

Table 1. Thermal and Physical Properties of Materials Studied

Scheme 1. Synthesis and structure of cyanate esters studied

Scheme 2. Reactions involved during the preparation of siliconized epoxy resin

Scheme 3. Reactions involved during the curing process of cyanate ester modified epoxy systems.

Figure 1. (a) Crystal structure of montmorillonite clay and (b) Conceptual 2-D view of polymer clay nanocomposites

Figure 2. Schematic view of cation exchanged organically modified MMT clay

Figure 3. FTIR spectra of (a) neat epoxy, (b) $\gamma$-APS cured epoxy, (c) siloxane modified epoxy, (d) pure cyanate ester (CE-2), (e) cyanate ester (CE-2)-siliconized epoxy taken 
after heating at $140{ }^{\circ} \mathrm{C}$ for 3 hours, (f) cyanate ester (CE-2)-siliconized epoxy cured with DDM at $140{ }^{\circ} \mathrm{C}$ for 3 hours and post cured at $200{ }^{\circ} \mathrm{C}$

Figure 4. DSC thermograms of (a) unfilled and (b) filled clay-cyanate ester and siloxane modified epoxy systems

Figure 5. TG curves of (a) unfilled and (b) filled clay-cyanate ester and siloxane modified epoxy systems

Figure 6. Heat distortion temperatures of hybrid clay-epoxy systems

Figure 7. Histogram of char yields of clay filled and toughened epoxy hybrid systems

Figure 8. Variation of $\tan \delta$ as a function of temperature of (a) unfilled and (b) filled clay-cyanate ester and siloxane modified epoxy systems

Figure 9. Water absorption of cured hybrid clay-epoxy systems

Figure 10. SEM micrographs of (a) neat epoxy, (b) $5 \mathrm{wt} \%$ clay reinforced epoxy, (c) 5 wt $\%$ clay with $10 \mathrm{wt} \%$ HTPDMS modified epoxy, (d) $5 \mathrm{wt} \%$ clay reinforced with 10 wt\% cyanate ester (CE-2) and 10\% HTPDMS modified epoxy

Figure 11. XRD patterns of (a) montmorillonite clay, (b) epoxy-clay (5\%) cured after swelling at $70{ }^{\circ} \mathrm{C}$ for 12 hours, (c) siliconized epoxy-clay (5\%) cured after swelling at 70 ${ }^{\circ} \mathrm{C}$ for 24 hours, (d) cyanate ester-siliconized epoxy-clay (5\%) cured after swelling at 70 ${ }^{\circ} \mathrm{C}$ for 24 hours, (e) epoxy-clay (5\%) cured after swelling at $70{ }^{\circ} \mathrm{C}$ for 24 hours 
Table 1. Thermal and Physical Properties of Materials Studied

\begin{tabular}{|l|l|l|l|}
\hline System & $\begin{array}{l}\text { Glass transition } \\
\left.\text { temperature }{ }^{\circ} \mathbf{C}\right)\end{array}$ & $\begin{array}{l}\text { Heat distortion } \\
\left.\text { temperature }{ }^{\circ} \mathrm{C}\right)\end{array}$ & $\begin{array}{l}\text { Water } \\
\text { absorption (\%) }\end{array}$ \\
\hline $\mathrm{A}$ & 165 & 153 & 0.12 \\
\hline $\mathrm{BC}_{0}$ & 164 & 145 & 0.11 \\
\hline $\mathrm{BC}_{1}$ & 164 & 143 & 0.10 \\
\hline $\mathrm{BC}_{3}$ & 162 & 141 & 0.08 \\
\hline $\mathrm{BC}_{5}$ & 161 & 140 & 0.06 \\
\hline $\mathrm{D}_{1} \mathrm{C}_{0}$ & 164 & 140 & 0.10 \\
\hline $\mathrm{D}_{2} \mathrm{C}_{0}$ & 163 & 141 & 0.11 \\
\hline $\mathrm{D}_{3} \mathrm{C}_{0}$ & 162 & 137 & 0.10 \\
\hline $\mathrm{D}_{1} \mathrm{C}_{1}$ & 162 & 138 & 0.08 \\
\hline $\mathrm{D}_{2} \mathrm{C}_{1}$ & 159 & 139 & 0.09 \\
\hline $\mathrm{D}_{3} \mathrm{C}_{1}$ & 158 & 136 & 0.08 \\
\hline $\mathrm{D}_{1} \mathrm{C}_{3}$ & 157 & 135 & 0.06 \\
\hline $\mathrm{D}_{2} \mathrm{C}_{3}$ & 153 & 136 & 0.06 \\
\hline $\mathrm{D}_{3} \mathrm{C}_{3}$ & 151 & 134 & 0.06 \\
\hline $\mathrm{D}_{1} \mathrm{C}_{5}$ & 154 & 132 & 0.05 \\
\hline $\mathrm{D}_{2} \mathrm{C}_{5}$ & 152 & 134 & 0.05 \\
\hline $\mathrm{D}_{3} \mathrm{C}_{5}$ & 151 & & \\
\hline
\end{tabular}

A - neat epoxy

$\mathrm{BC}_{\mathrm{x}}-$ Organoclay reinforced siliconized epoxy

$D_{y} C_{x}-$ Organoclay reinforced cyanate ester-siliconized epoxy

$\mathrm{x} \quad$ - Weight percentage of organoclay

y - type of cyanate ester (CE-1, CE-2 and CE-3) used in the hybrid system 

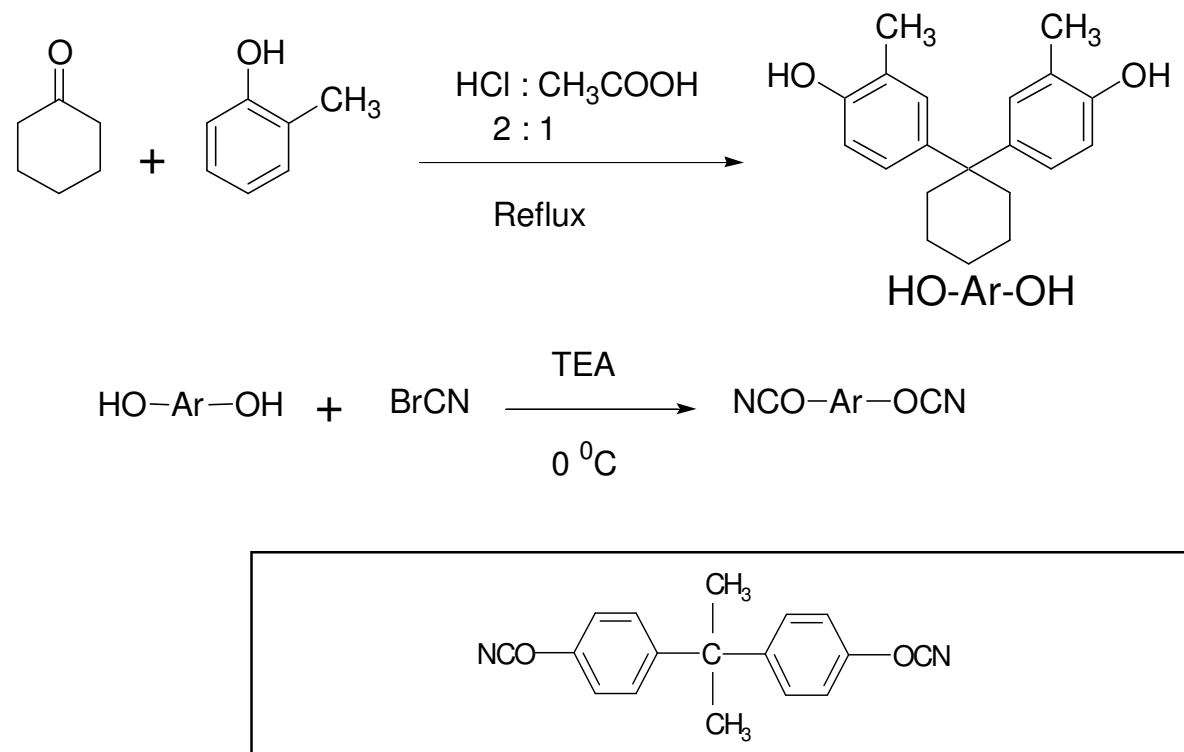

CE-1

4,4'-dicyanato-2,2-diphenylpropane

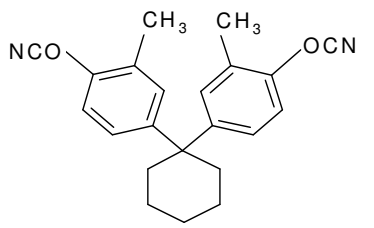

CE-2

1,1-bis(3-methyl-4-cyanatophenyl) cyclohexane<smiles>COc1cccc(C#N)c1</smiles>

CE-3

1,3-dicyanatobenzene

Scheme 1. Synthesis and structure of cyanate esters 


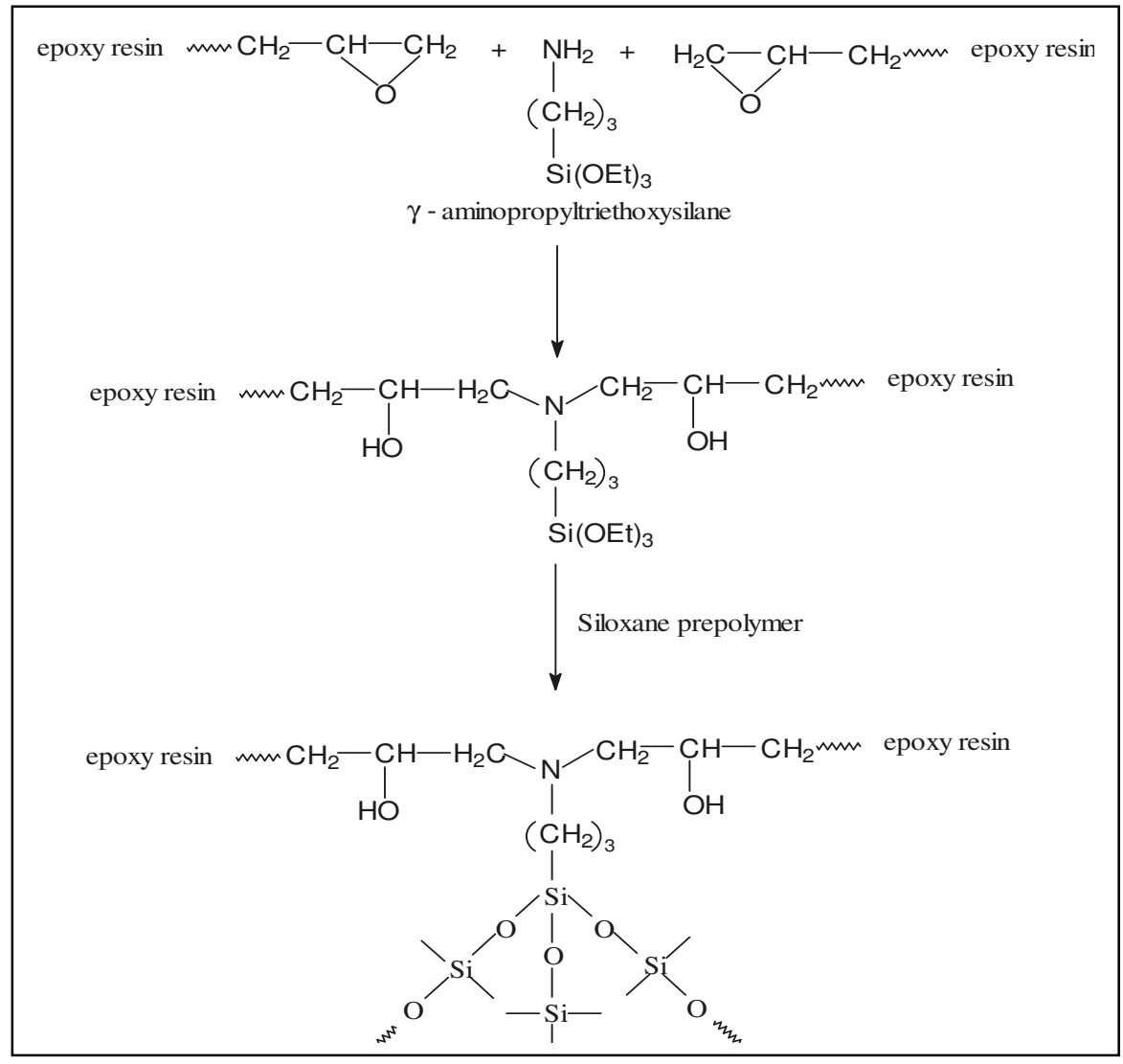

Scheme 2. Reactions involved during the preparation of siliconized epoxy resin 


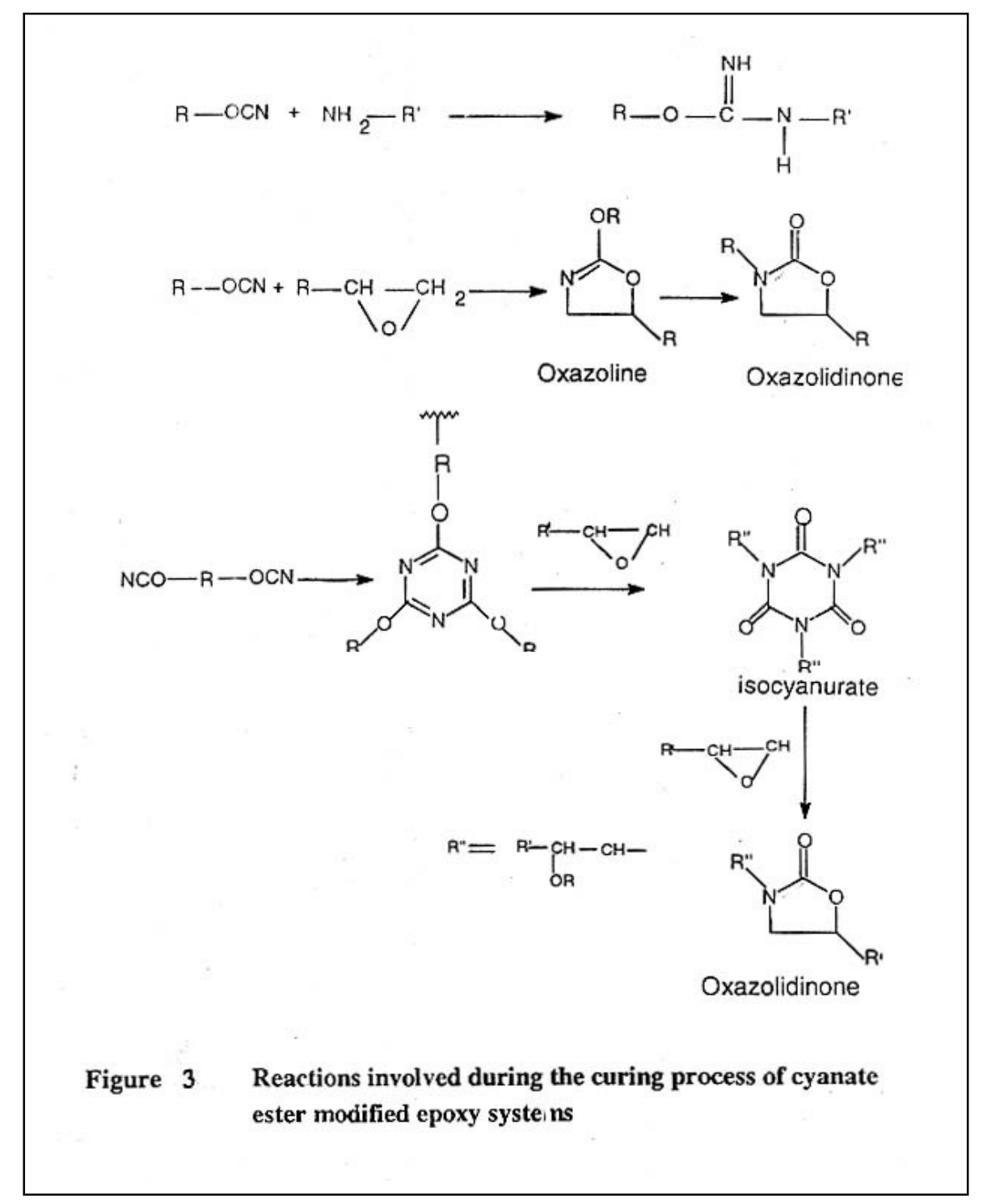

Scheme 3. Reactions involved during the curing process of cyanate ester modified siliconized epoxy systems.

(a) 


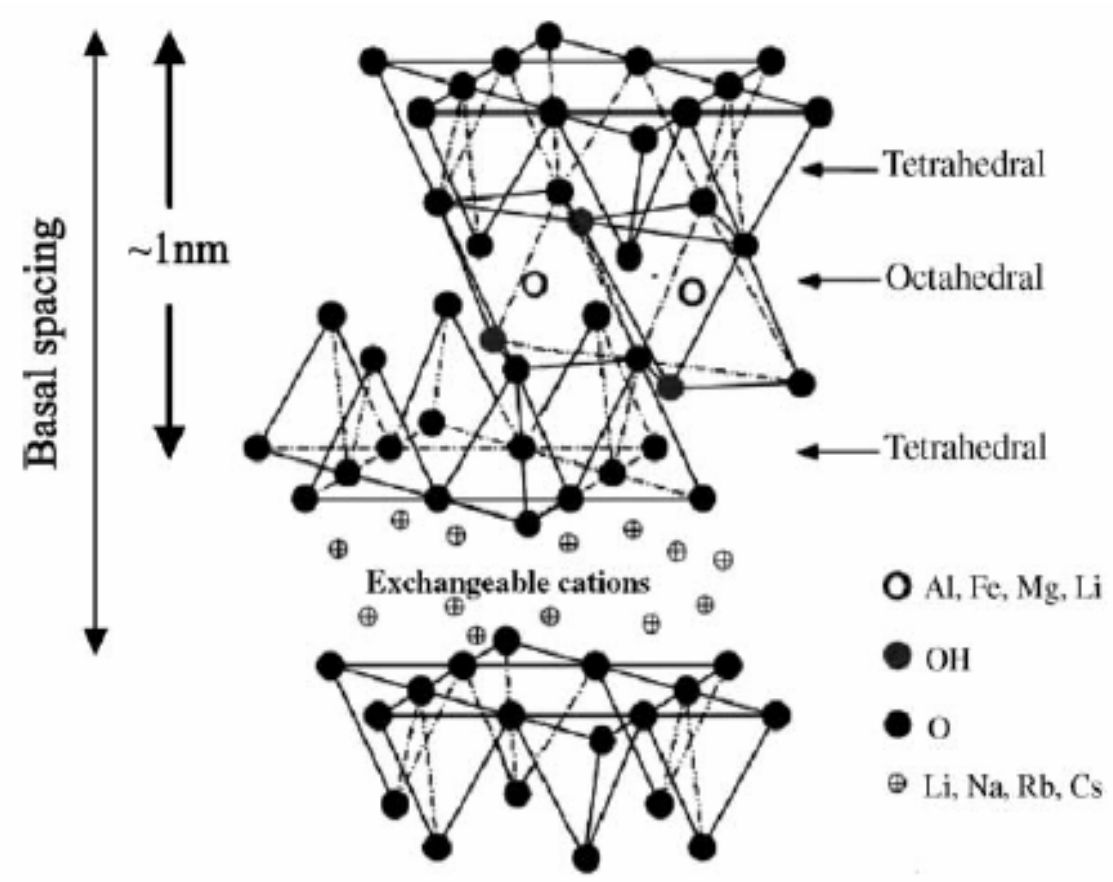

(b)

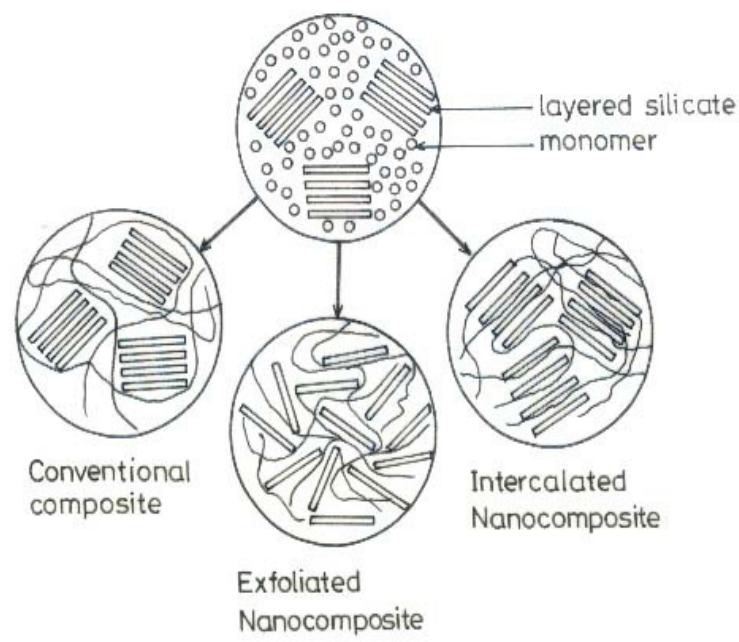

Figure 1. (a) Crystal structure of montmorillonite clay and (b) Conceptual 2-D view of polymer clay nanocomposites 


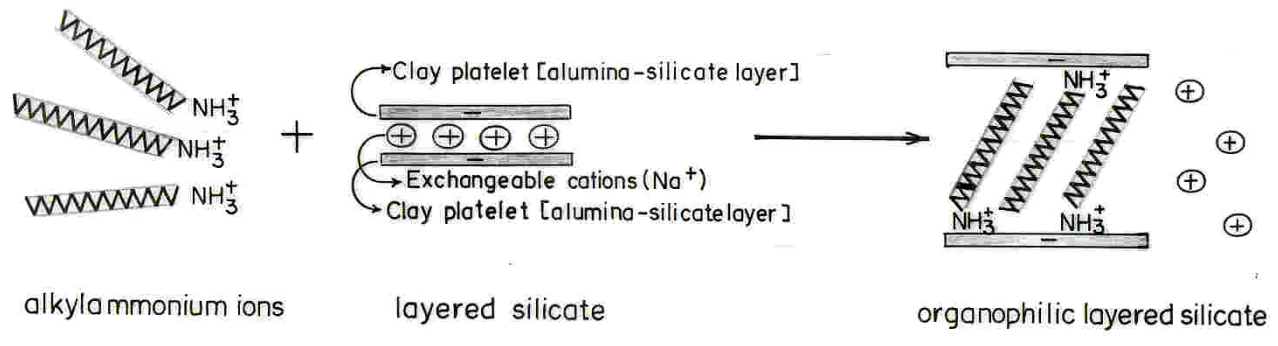

Figure 2. Schematic view of cation exchanged organically modified MMT clay 


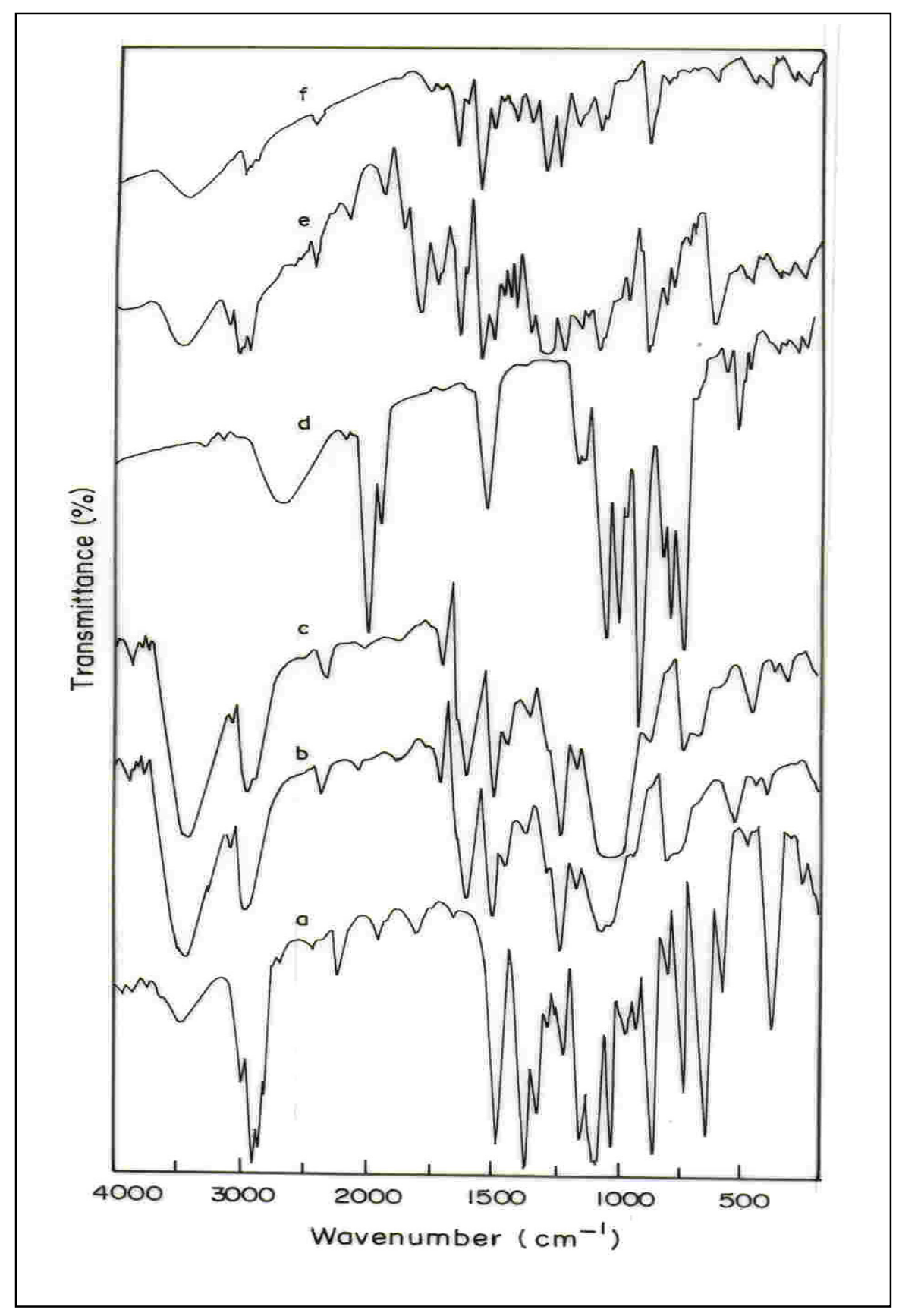

Figure 3. FTIR spectra of (a) neat epoxy, (b) $\gamma$-APS cured epoxy, (c) Siloxane modified epoxy, (d) pure cyanate ester (CE-2), (e) cyanate ester (CE-2)-siliconized epoxy taken after heating at $140{ }^{\circ} \mathrm{C}$ for 3 hours, (f) cyanate ester (CE-2)-siliconized epoxy cured with DDM at $140{ }^{\circ} \mathrm{C}$ for 3 hours and post cured at $200{ }^{\circ} \mathrm{C}$ 
(a)

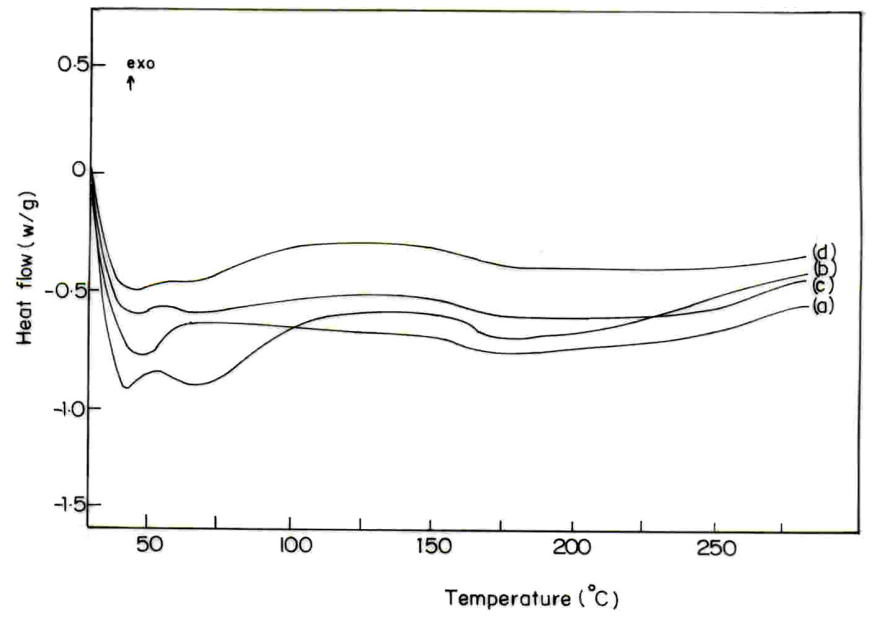

(b)

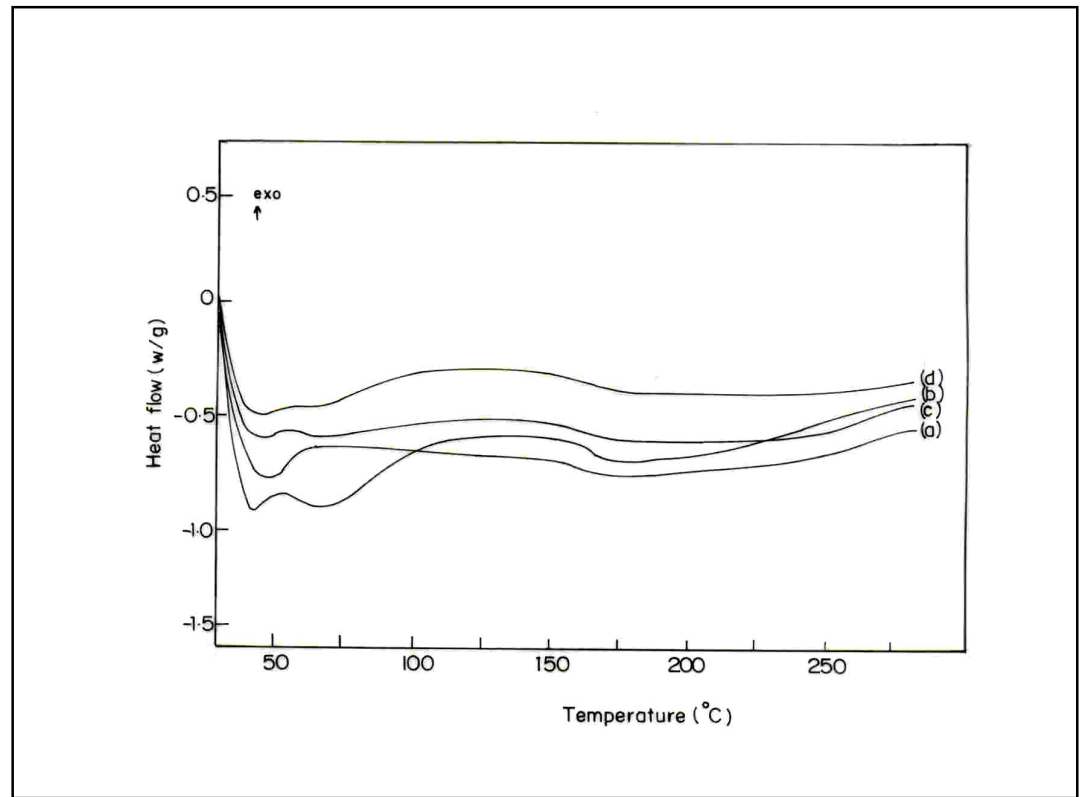

Figure 4. DSC thermograms of (a) unfilled and (b) filled clay-cyanate ester and siloxane modified epoxy systems 
(a)

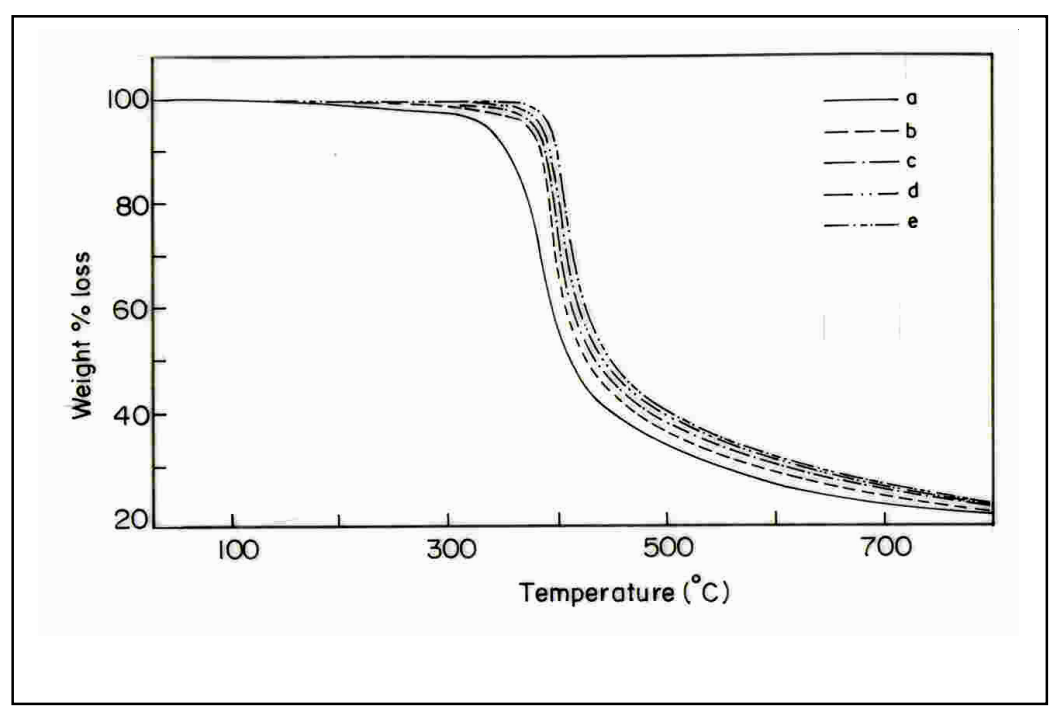

(b)

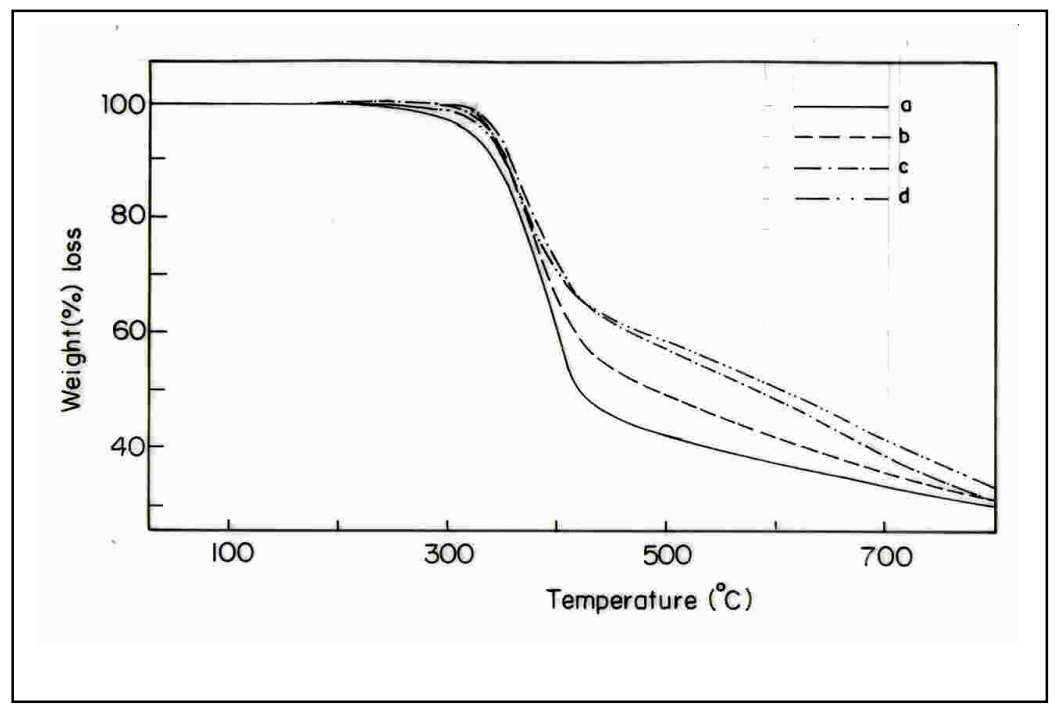

Figure 5. TG curves of (a) unfilled and (b) filled clay-cyanate ester and siloxane modified epoxy systems 


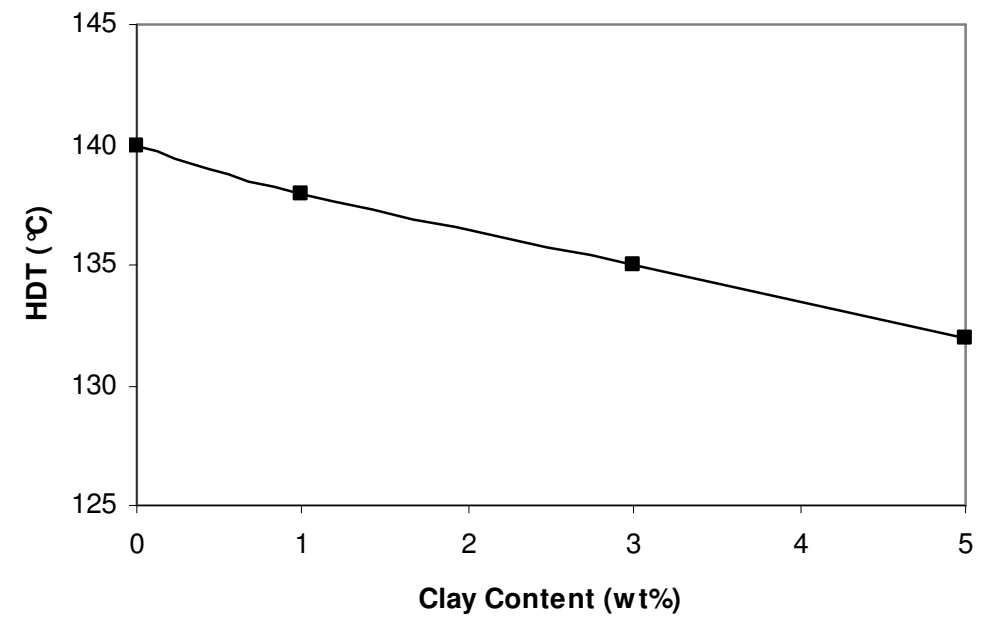

Figure 6. Heat distortion temperatures of hybrid clay-epoxy systems 


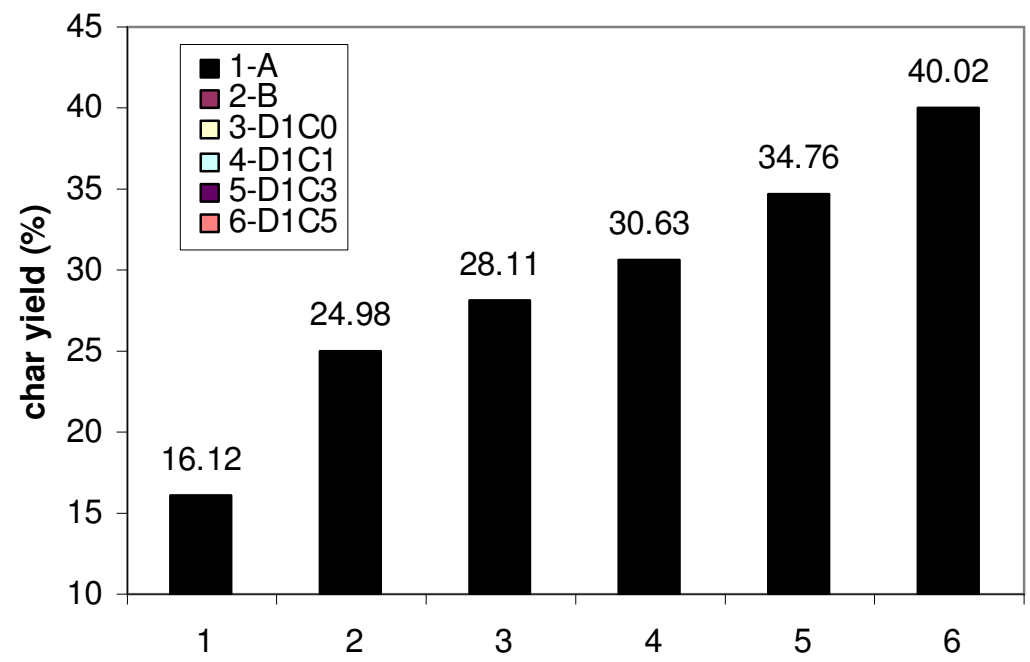

Figure 7. Histogram of char yields of clay filled and toughened epoxy hybrid systems 
(a)

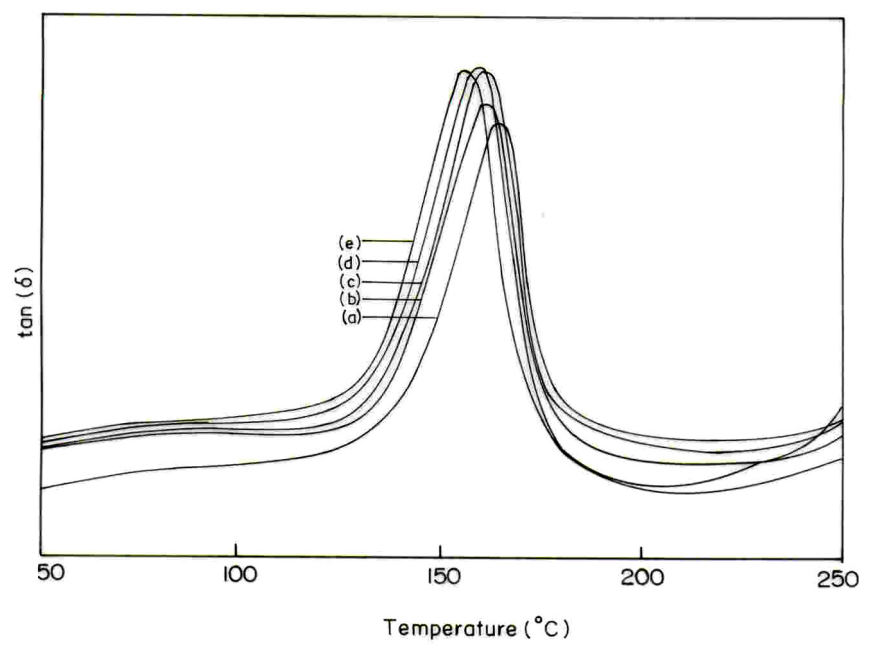

(b)

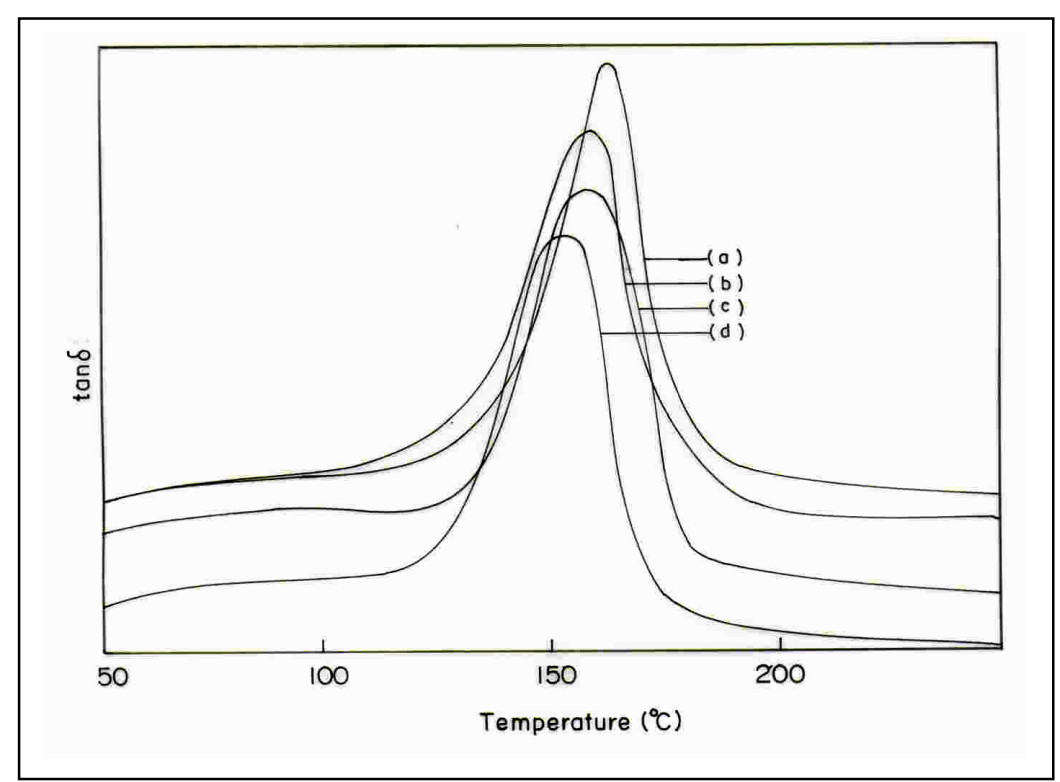

Figure 8. Variation of $\tan \delta$ as a function of temperature of (a) unfilled and (b) filled clay-cyanate ester and siloxane modified epoxy systems 


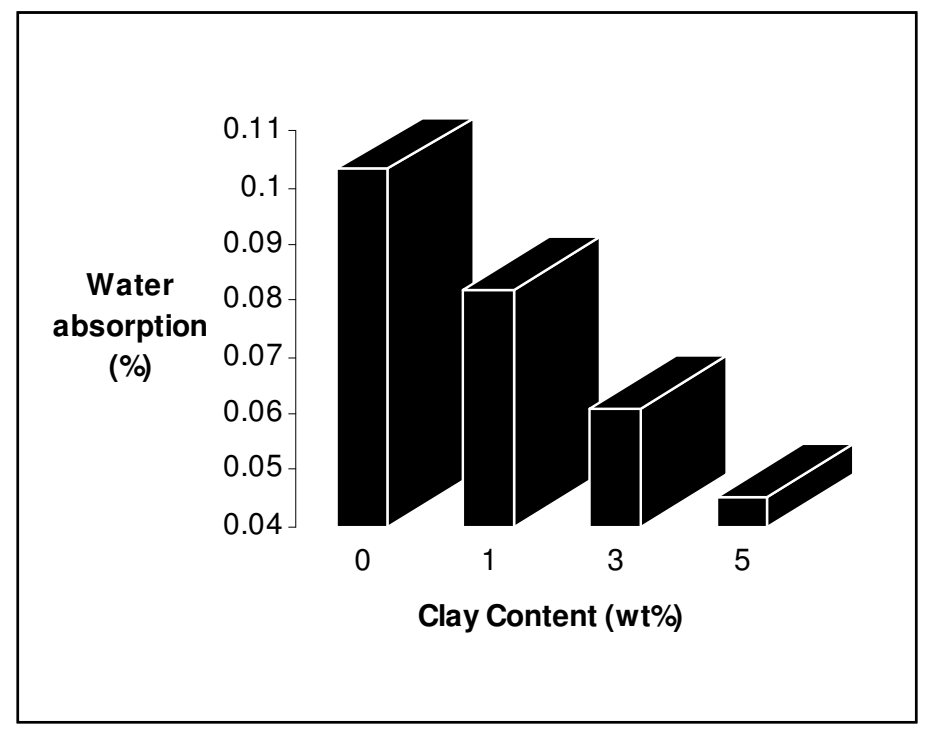

Figure 9. Water absorption of cured hybrid clay-epoxy systems 


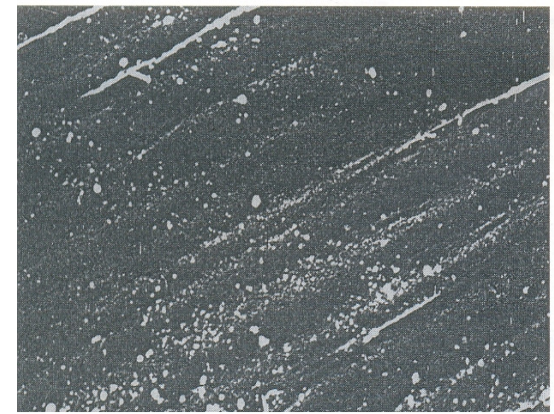

(a)

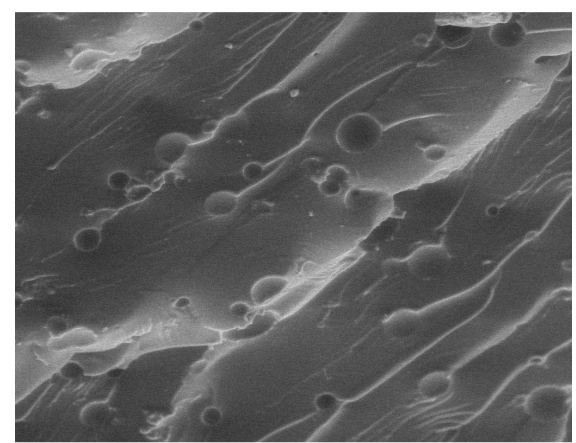

(c)

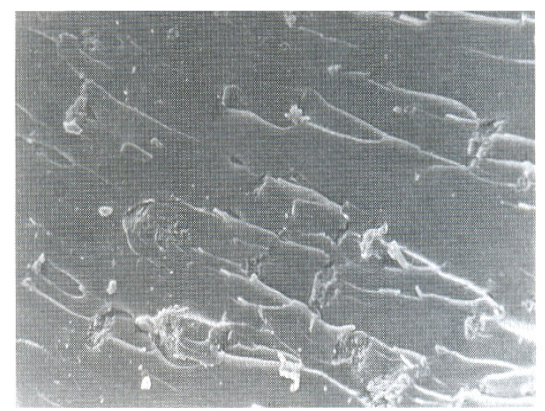

(b)

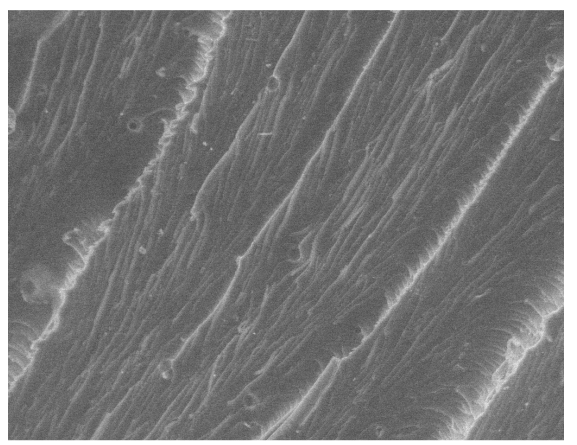

(d)

Figure 10. SEM micrographs at $50 \mu \mathrm{m}$ of (a) neat epoxy, (b) $5 \mathrm{wt} \%$ clay reinforced epoxy, (c) 5 wt\% clay reinforced with 10 wt\% HTPDMS modified epoxy, (d) 5 wt \% clay reinforced with $10 \mathrm{wt} \%$ cyanate ester (CE-2) and 10\% HTPDMS modified epoxy 


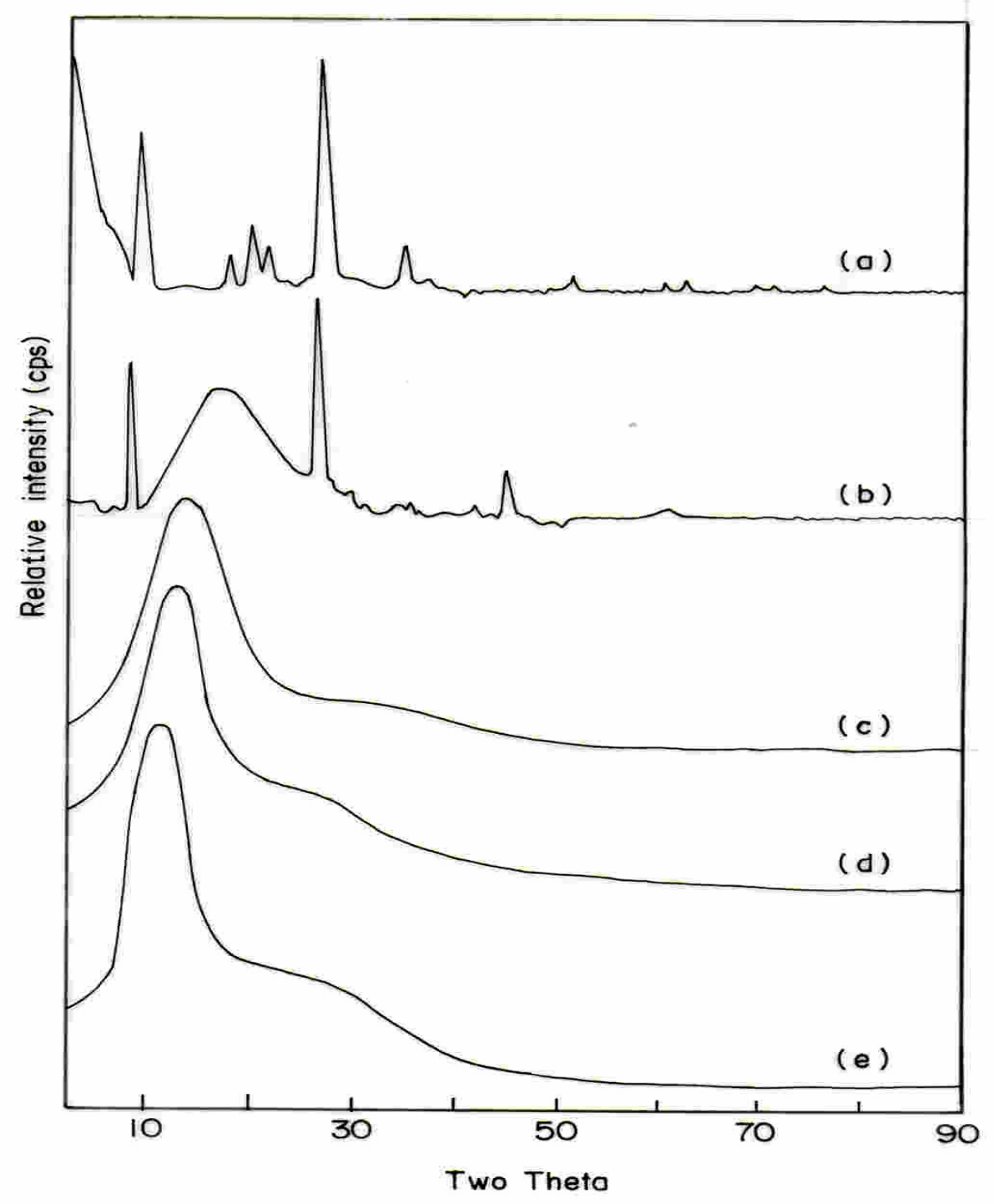

Figure 11. XRD patterns of (a) montmorillonite clay, (b) epoxy-clay (5\%) cured after swelling at $70{ }^{\circ} \mathrm{C}$ for 12 hours, (c) siliconized epoxy-clay (5\%) cured after swelling at $70{ }^{\circ} \mathrm{C}$ for 24 hours, (d) cyanate ester-siliconized epoxy-clay (5\%) cured after swelling at $70{ }^{\circ} \mathrm{C}$ for 24 hours, (e) epoxy-clay $(5 \%)$ cured after swelling at $70{ }^{\circ} \mathrm{C}$ for 24 hours 


\section{References}

1 Messersmith PB, Strupp SI. J Mater Res 1992; 7: 2559

2 Giannelis EP. Adv Mater 1996; 8: 29

3 Zilg C, Mulhaupt R, Finter J. Macromol Chem Phys 1999; 200: 661

4 Schmidt H. J Non-Cryst Solids 1985; 73: 681

5 Novak B. M Adv Mater 1993; 5: 422

6 Pinnavaia TJ. Science 1983; 220: 365

7 Jacob MME, Hackett E, Giannelis EP. J Mater Chem 2003; 1: 1

8 Kawasumi, M., Hasegawa, N., Kato, M., Usuki, A. and Okada, A., (1997)

Macromolecules, 30: 6333-6338.

9 Robello DR, Yamaguchi N, Blanton T, Bames C. J Amer Chem Soc 2004; 126: 8118

10 Usuki A, Kojima Y, Kawaskumi M, Okada A, Fukushima Y, Kurauchi T, Kamigaito

O. J Mater Res 1993; 8: 1179

11 Kojima Y, Usuki A, Kawasumi M, Okada A, Fukushima Y, Kurauchi T, Kamigaito

O. J. Mater Res 1993; 8: 1185

12 Salahuddin NA. Polym Adv Technol 2004; 15: 251

13 Cheng KC, Lai KC, Chiu WJ. J Appl Polym Sci. 1999; 71: 721

14 Lee H, Neville K. Handbook of Epoxy Resins. New York: McGraw-Hill; 1967

15 Wong CP, Adv Polym Sci 1988; 84: 63

16 Liu YL, Wei WL, Hsu KY, Ho WH. Thermochim Acta 2004; 412: 139

17 Messersmith PB, Giannelis EP. Chem Mater 1994; 6: 1719

18 Wang MS, Pinnavaia TJ. Chem Mater 1994; 6: 468

19 Shi H, Lan T, Pinnavaia TJ. Chem Mater 1996; 8: 1584

20 Lan T, Kaviratna PD, Pinnavaia TJ. Chem Mater 1995; 7: 2144

21 Ashok Kumar A, Alagar M, Rao RMVGK. Polymer 2002; 43: 693

22 Dinakaran K, Alagar MK. Poly Adv Tech 2003; 14: 574

23 Hamerton I, Hay JN. Polym Int 1998; 47: 465

24 Ganguli S, Dean D, Jordan K, Price G, Vaia R. Polymer 2003; 44: 1315

25 Hamerton, I. 'Properties of unreinforced cyanate ester matrix resins' in I Hamerton

(Ed.) Chemistry and Technology of Cyanate Ester Resins, Blackie Academic and

Professional (1994), pp. 193-229 
26 Hisue GH, Wang WJ, Chang FC. J Appl Polym Sci 1999; 73: 1231

27 Lee A, Lichtenhan JD. J Appl Polym Sci 1999; 73: 1993

28 Baumann, J., Beer, R., Calzaferri, G. and Waldeck, B. 1989 J. Phys. Chem., 93: 22922302.

29 Kornmann, X., Thmann, R., Mulhaupt, R., Finter, J. and Berglund, L.A. (2001) In

Proceedings of the NRCC/IMI International Symposium on Polymer Nanocomposites

Sciences and Technology, Polymer Nanocomposites,

Montreal, Canada.

30 Becker, O., Varely, R.J. and Simon, G.P. 2001, Polymer, 43: 4365-

4373.

31Kornmann, X., Berglund, L.A. and Lindberg, H. 2000, Mat. Res. Soc. Symp. Proc., 628: 1181 .

32 Hussain, M., Varley, R.J., Mathys, Z., Cheng, Y.B. and Simon, G.P. 2004, J. Appl.

Polym. Sci., 91:1233-1253.

33 Park, J.H. and Jana, S.C. 2003, Macromolecules, 36: 2758-2768.

34 Hussain M, Varley RJ, Mathys Z, Cheng YB, Simon GP. J Appl Polym Sci 2004; 91: 1233

35 Becker O, Varely RJ, Simon GP. Polymer 2001; 43: 4365 